\title{
Rancang Bangun Sistem Alarm untuk Mencegah Kavitasi pada Condensate Extraction Pump di PT. Indonesia Power Unit Jasa Pembangkit (UJP) Jawa Tengah 2 Adipala
}

\author{
Agus Slamet*, Wahyu Djalmono, Yogi Prakasa, Farika Tono Putri \\ Jurusan Teknik Mesin, Politeknik Negeri Semarang \\ Jl. Prof. Sudarto, Tembalang, Kec. Tembalang, Kota Semarang, Jawa Tengah \\ *E-mail: agussmg13@gmail.com
}

\begin{abstract}
Abstrak
PT Indonesia Power Unit Jasa Pembangkit (UJP) Jawa Tengah 2 Adipala merupakan perusahaan yang bergerak dalam bidang pembangkitan energi listrik dengan daya uap. Untuk memenuhi kebutuhan produksi sebesar 1 x 660 MW, unit-unit pada PLTU ini bekerja secara kontinyu dan saling terhubung salah satunya yaitu Condensate Extraction Pump(CEP). Permasalahan yang ada yaitu bila terjadi kavitasi pada CEP ini sering terlambat untuk diketahui. Hal ini disebabkan karena tidak adanya sistem peringatan atau deteksi terjadinya kavitasi pada CEP. Mengingat dampak kavitasi yang sangat merugikan, mulai dari berkurangnya performa pompa hingga rusaknya komponen pompa, maka terjadinya kavitasi pada pompa ini harus dicegah. Tujuan dari penelitian ini adalah merancang sebuah system alarm untuk mencegah kavitasi. Perancangan suatu program alarm saat muncul potensi kavitasi pada pompa dengan konsep dasar menggunakan Net Positive Suction Head required (NPSHr) sebagai ambang batas diharapkan dapat mencegah terjadinya kerusakan pompa akibat kavitasi. Memanfaatkan nilai NPSHr untuk mencegah kavitasi merupakan metode yang berbeda bila dibandingkan dengan penelitian lain yang menggunakan sinyal getaran. Metode penelitian meliputi, identifikasi masalah, studi pustaka, analisis perancangan, pembuatan program dan pengujian. Program dibuat menggunakan aplikasi Visual Basic. Untuk memvalidasi program bekerja sesuai perencanaan dilakukan pengujian dengan memasukkan variasi parameter berupa temperatur air dan ketinggian air sesuai data aktual dengan range masing - masing yaitu $25^{\circ} \mathrm{C}$ hingga $60^{\circ} \mathrm{C}$ dan $300 \mathrm{~mm}-1300$ $\mathrm{mm}$. Tekanan dalam kondensor nilainya tetap $-80 \mathrm{kPa}$ atau $21.325 \mathrm{kPa}$ dalam tekanan absolut. Head loss dalam instalasi perpipaan dihitung nilainya didapatkan $0.7196 \mathrm{~m}$. Hasil pengujian program alarm mampu mengolah nilai NPSHa dan menampilkannya dalam bentuk grafik yang fluktuatif sesuai dengan tingkat keadaannya serta alarm berbunyi saat nilai Net Positive Suction Head available(NPSHa) dibawah nilai NPSHr atau pompa beroperasi dalam kondisi kavitasi.
\end{abstract}

Received: 23-03-2020; Accepted: 16-04-2020; Published online: 23-04-2020

Kata kunci: alarm; condensate extraction pump; kavitasi

\begin{abstract}
PT Indonesia Power is power plant located in Central Java Adipala enganged in electric plant utilizing steam power. To meet the production requirement of $1 \times 660 \mathrm{MW}$, units at the PLTU work countinously and interconnected and one of them is Condensate Extraction Pump (CEP). Late detection of cavitation in CEP become a problem. The problem happen because lack of alarm system and cavitation detection in CEP. Given the damage of cavitation which range from pump performance reduction to pump component damage, therefore cavitation occurance should be prevented. The aim of this research is to design an alarm system for cavitation prevention. Design of an alarm program when there are possibility of cavitation arise using Net Positive Suction Head required (NPSHr)as threshold to prevent pump damage due to cavitation. NPSHr value to prevent cavitation is a different method from other research which use vibration signal. Research method consist of problem iidentification, literaturw review, design analysis, program design and testing. Program is made using Visual Basic. Testing with actual parameter variation like water temperature value $25^{\circ} \mathrm{C}$ to $60^{\circ}$ Cand water level value $300 \mathrm{~mm}$ to $1300 \mathrm{~mm}$ is done to validate program design. Condensor pressure on steady value $-80 \mathrm{kPa}$ or $21.325 \mathrm{kPa}$ on absolute pressure conversion. Calculated head loss in piping installation value $0.7196 \mathrm{~m}$. Alarm testing result that it is capable to process and display NPSHa value in form of fluctuate graphic and alarm is activated when Net Positive Suction Head available (NPSHa) value below NPSHr or when cavitation occur.
\end{abstract}

Keywords: alarm; condensate extraction pump; cavitation

\section{Pendahuluan}

PT Indonesia Power UJP Jawa Tengah 2 Adipala merupakan perusahaan yang bergerak dalam bidang pembangkitan energi listrik yang memanfaatkan daya uap.Untuk menghasilkan energi listrik, unit-unit saling terhubung dan bekerjasama membentuk suatu sistem.Salah satu unit tersebut yaitu CEP.Kavitasi merupakan permasalahan yang sering 
ditemui pada unit instalasi pompa CEP, seringkali kavitasi yang terjadi terlambat untuk dideteksi.Penyebab permasalahan tersebut karena tidak adanya sistem alarm sebagai peringatan dan deteksi dini adanya kavitasi di unit CEP PT Indonesia Power Adipala.Kasus kavitasi di PT Indonesia Power Adipala berdampak pada timbulnya suara bising dari pompa yang bekerja sampai dengan menurunnya unjuk kerja pompa. Apabila kavitasi dibiarkan terus menerus tanpa deteksi maka akan merusak bagian vital pada pompa terutama impeller pompa.

Kajian deteksi kavitasi telah banyak dilakukan dengan berbagai macam variasi metode antara lain dengan metode analisa getaran [1], metode spektrum getaran dan spektrum envelope menggunakan fast fourier transform (FFT) [2] dan metode kecerdasan buatan dengan teori Principal Component Analysis(PCA) dari ekstraksi domain waktu dan domain frekuensi getaran [3]. Metode lain yang dilakukan oleh peneliti luar negeri antara lain deteksi kavitasi dengan teori Probability Density Analysis (PDA), Root Mean Square (RMS) dan standar deviasi pada data getaran [4]. Penelitian lain menggabungkan analisa spektrum getaran dengan spektrum suara akustik untuk mendeteksi adanya kavitasi pada pompa dengan variasi kecepatan [5]. Gabungan metode kecerdasan buatan wavelet packet decomposition (WPD), PCA dan Radial Basic Function (RBF) untuk menganalisa sinyal gangguan pada pompa [6]. Sedangkan pada penelitian ini mendeteksi kavitasi pompa dengan metode perbandingan nilai NPSHa dan NPSHr pada sistem CEP kemudian hasil deteksi tersebut diterjemahkan ke dalam sistem alarm dengan basis software Visual Basic. Penelitian ini bertujuan untuk merancang dan membangun sistem alarm kavitasi pada unit CEP PT Indonesia Power Adipala. Metode pada penelitian ini sangat sederhana dan dapat dibuat dengan biaya yang sangat murah apabila dibandingkan dengan metodemetode deteksi kavitasi lain yang telah dijelaskan di atas sehingga mudah untuk diaplikasikan.

\section{Material dan metodologi}

Penelitian dilakukan di PT Indonesia Power Adipala pada unit CEP.CEP merupakan unit pompa yang berfungsi untuk menyalurkan air hasil kondensasi uap dalam kondensor menuju deaerator.Tabel 1 menunjukkan spesifikasi pompa yang ada di unit CEP PT Indonesia Power Adipala.

Tabel 1. Spesifikasi unit pompa CEP di PT Indonesia Power Adipala [7]

\begin{tabular}{ll}
\hline Data & Keterangan \\
\hline Pump Type & Vertical, multi stage, centrifugal \\
Pump Model & C720II-4 \\
Quantity & $1823 \mathrm{t} / \mathrm{h}$ \\
Pumping Head & $325 \mathrm{~m}$ \\
Efficiency & $84 \%$ \\
Net Positive Suction Head Required at the Centerline of & $5.5 \mathrm{mH}_{2} \mathrm{O}$ \\
the first-stage Impeller (NPSHr) & \\
Guarantee Value of Vibration at the Bearing Seat & $0.05 \mathrm{~mm}$ (pada kondisi operasi normal) \\
(Double-amplitude Value) & \\
Rotating Speed & $1480 \mathrm{r} / \mathrm{min}$ \\
Pump Shaft Power & $1922 \mathrm{~kW}$ \\
Manufature & Hunan Xiangdian Changsha Water Pumps Co., Ltd. \\
\hline
\end{tabular}

Metode penelitian terdiri dari beberapa langkah antara lain identifikasi masalah, identifikasi solusi masalah, pengumpulan data-data penelitian dari lapangan dan karya ilmiah, analisa data perhitungan NPSHa dan head loss, 
pembuatan program (desain interface dan coding program) serta pengujian yang terdiri dari pengujian program dan validasi nilai tekanan jenuh. Kavitasi yang terlambat dideteksi pada unit CEP PT Indonesia Power Adipala adalah permasalahan yang telah diidentifikasi oleh peneliti. Dari permasalahan tersebut diperoleh solusi untuk membuat sistem alarm deteksi dini kavitasi dengan menggunakan perbandingan nilai NPSHa dan NPSHr. Pengumpulan data dilakukan untuk analisa perhitungan yang diperlukan. Data dikumpulkan dengan metode studi lapangan untuk mengetahui instalasi perpipaan untuk menghitung head loss mayor, head loss minor, head absolut pada permukaan fluida, head static suction, tekanan uap jenuh dan NPSHr. Penelitian dilakukan dalam jangka waktu 8 bulan dari bulan Juni 2018 sampai dengan Febuari 2019. Pada timeline waktu tersebut data yang berhasil dikumpulkan antara lain tekanan pada kondensor dengan nilai $80 \mathrm{KPa}$ pada pressure gauge atau $21.325 \mathrm{KPa}$ absolut, temperatur air pada kondensor antara $25^{\circ} \mathrm{C}$ sampai dengan $60^{\circ} \mathrm{C}$, ketinggian air pada kondensor berkisar antara $300 \mathrm{~mm}$ sampai dengan $1300 \mathrm{~mm}$ serta data instalasi perpipaan yang bisa dilihat pada Tabel 2 .

Tabel 2. Spesifikasi perpipaan unit pompa CEP di PT Indonesia Power Adipala

\begin{tabular}{cccc}
\hline Pipa & Panjang (m) & Diameter $(\mathbf{m})$ & Material \\
\hline Pipa A-B, H-I & 0.8 & 0.6 & Carbon Steel \\
Pipa C-G & 3.6 & 0.6 & Carbon Steel \\
Pipa F-J & 3.3 & 0.6 & Carbon Steel \\
Pipa K-L & 1.6 & 0.6 & Carbon Steel \\
Pipa M-N & 2.6 & 0.6 & Carbon Steel \\
Pipa O-P & 0.3 & 0.6 & Carbon Steel \\
Pipa V-S & 1.6 & 0.6 & Carbon Steel \\
Pipa T-U, W-X & 0.8 & 0.6 & Carbon Steel \\
\hline
\end{tabular}

Selain panjang dan diameter pipa pada instalasi pipa dilengkapi juga dengan komponen-komponen lain seperti elbow, pipe exit, gate valve strainer dan tees. Spesifikasi dan jumlah komponen tersebut dapat dilihat pada Tabel 3.Gambar 1 menunjukkan instalasi perpipaan dari outlet kondensor sampai dengan inlet CEP. Instalasi tersebut menggambarkan spesifikasi perpipaan pada data Tabel 2 dan Tabel 3.

Tabel 3. Spesifikasi komponen perpipaan unit pompa CEP di PT Indonesia Power Adipala

\begin{tabular}{ccc}
\hline Komponen & Jumlah & Minor Loss Coefficient $\left(\mathbf{K}_{\mathbf{L}} \mathbf{)}\right.$ \\
\hline Elbow $90^{0}$ & 7 & 0.9 \\
Pipe Exit & 2 & 1.0 \\
Gate Valve Fully Open & 1 & 0.2 \\
Strainer & 1 & 1.72 \\
Tees & 2 & 2.0 \\
\hline
\end{tabular}

Data spesifikasi perpipaan tersebut dapat digunakan untuk menghitung nilai head loss mayor dan head loss minor. Nilai hasil perhitungan head loss mayor pada instalasi CEP PT Indonesia Power Adipala sebesar 0.0176 m sedangkan hasil perhitungan head loss minor sebesar $0.702 \mathrm{~m}$. Nilai head loss total diperoleh dari penjumlahan antara head loss mayor dengan head loss minor dan diperoleh nilai sebesar $0.7196 \mathrm{~m}$. 
Data yang diperlukan untuk analisa NPSHa antara lain head absolut pada permukaan fluida (ha), head static suction (hs), head loss total (hl) dan tekanan uap jenuh (hvap). Berdasarkan data yang diperoleh nilai ha dikonversikan dari tekanan rata-rata kondensor sebesar $80 \mathrm{KPa}$ pressure gauge kedalam satuan meter yaitu sebesar $2.17 \mathrm{~m}$.Nilai hs diperoleh dari penjumlahan antara tinggi pipa CEP dengan level air rata-rata sehingga diperoleh nilai hs sebesar $5.3 \mathrm{~m}$. Tekanan uap jenuh berdasarkan temperatur kondensat di lapangan berkisar antara $25^{\circ} \mathrm{C}$ sampai $60^{\circ} \mathrm{C}$ didapatkan dari tabel air jenuh. Untuk temperatur kondensat $25^{\circ} \mathrm{C}$ besarnya tekanan jenuhnya $3.169 \mathrm{kPa}$ atau dalam satuan head besarnya hvap adalah 0,32 m. Data-data tersebut kemudian dimasukkan dalam persamaan (1) untuk menghitung nilai NPSHa [8].Dari hasil perhitungan didapat nilai NPSHa unit CEP PT Indonesia Power Adipala sebesar 6.4303 m.

NPSHa $=h a+h s-h l-h v a p$

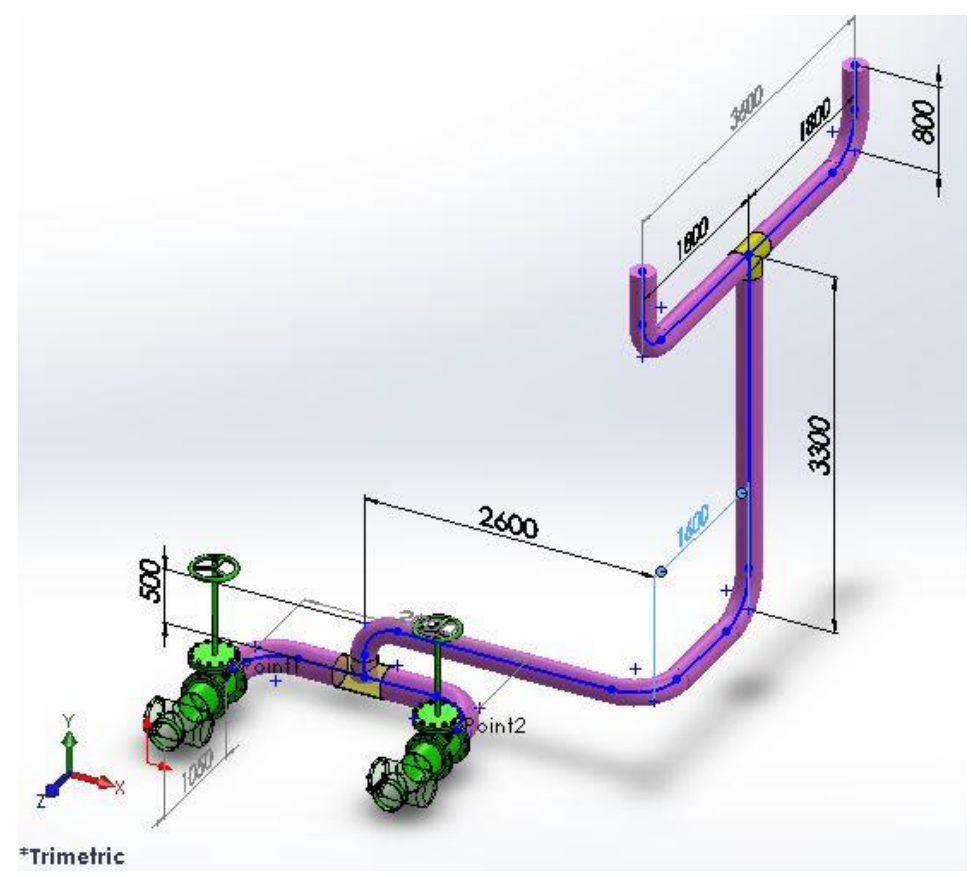

Gambar 1. Ilustrasi spesifikasi perpipaan pada unit CEP PT Indonesia Power Adipala

Program sistem alarm disusun dengan menggunakan software Visual Basic. Program ini terdiri dari 1 form utama (form 1) dan 3 form pendukung ( form 2, form 3dan form 4) serta 2 module yaitu module untuk koneksi ke database dan module untuk simulasi program.

Gambar 2 menunjukkan form utama yang berfungsi sebagai muka dalam program alarm untuk mencegah kavitasi pada CEP yang dibuat. Form ini menampilkan data-data parameter (data pengukuran) untuk perhitungan NPSH secara real time. Selain itu form ini juga menampilkan grafik hasil perhitungan NPSH yang telah diolah pada form yang lain. Form 2 merupakan salah satuform pendukung yang memiliki fungsi mehitung nilai NPSHadapat dilihat pada Gambar 3. Form3 yang memiliki fungsi untuk melakukan perhitungan nilai tekanan jenuh berdasarkan nilai temperatur air dan form 4 yang berfungsi untuk menghasilkan bunyi alarm apabila hasil perhitungan nilai NPSHa dari Form 2 dibawah NPSHr dapat dilihat pada Gambar 4 dan Gambar 5. 
Agus Slamet, dkk./Jurnal Rekayasa Mesin p-ISSN: 1411-6863, e-ISSN: 2540-7678

Vol.15|No.1|66-74|April|2020

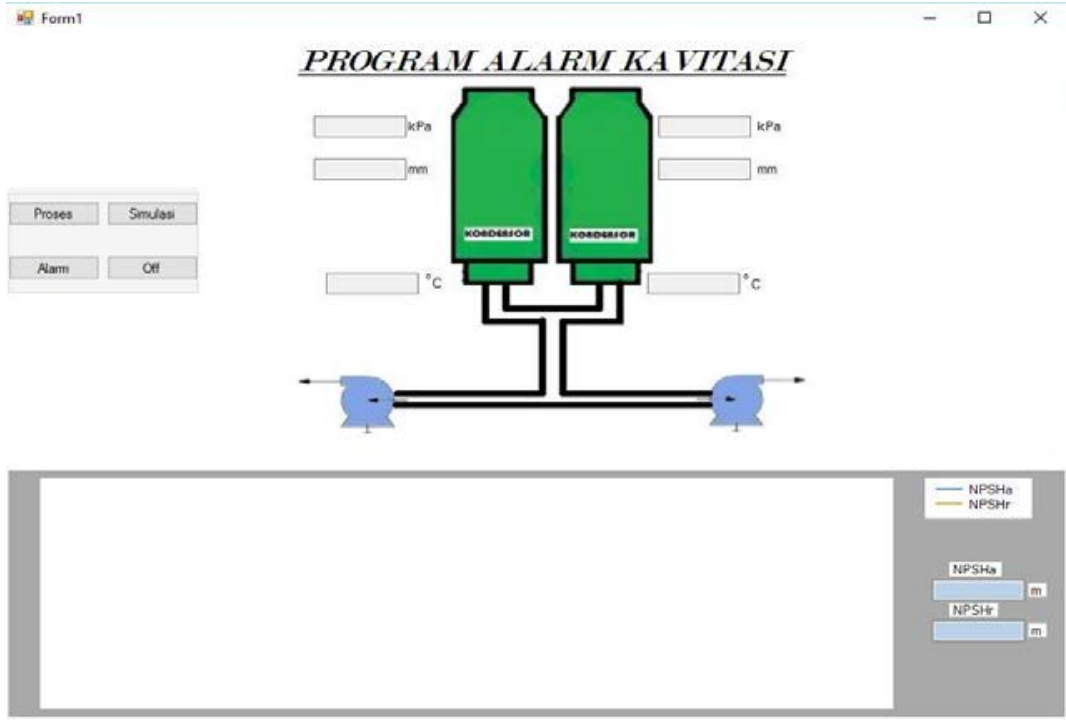

Gambar 2.Form utama sistem alarm kavitasi

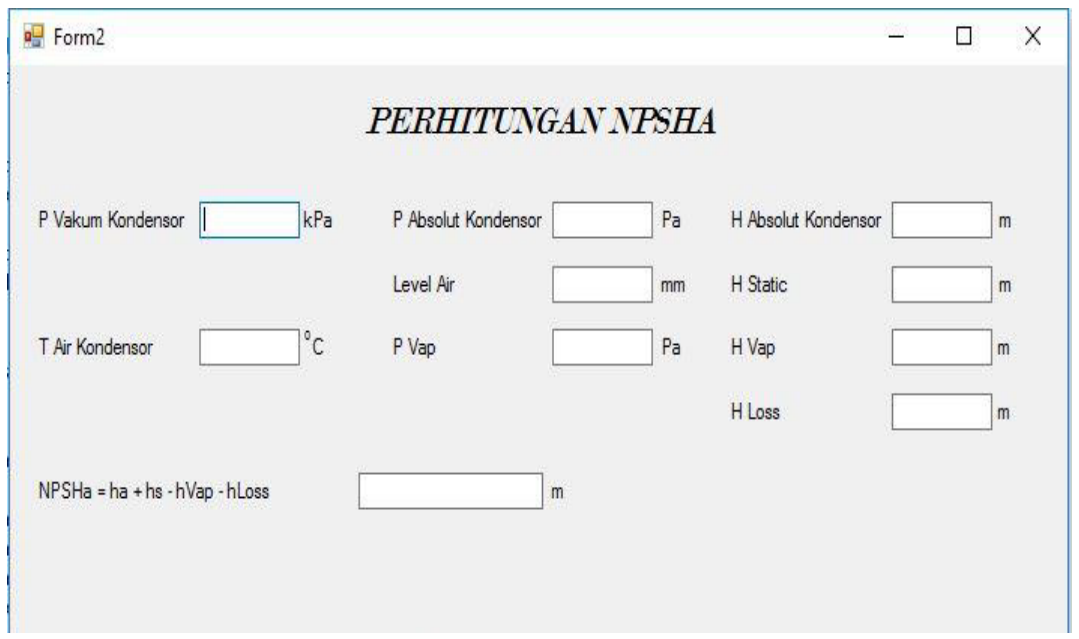

Gambar 3.Form pendukung 2 berfungsi untuk menghitung nilai NPSHa

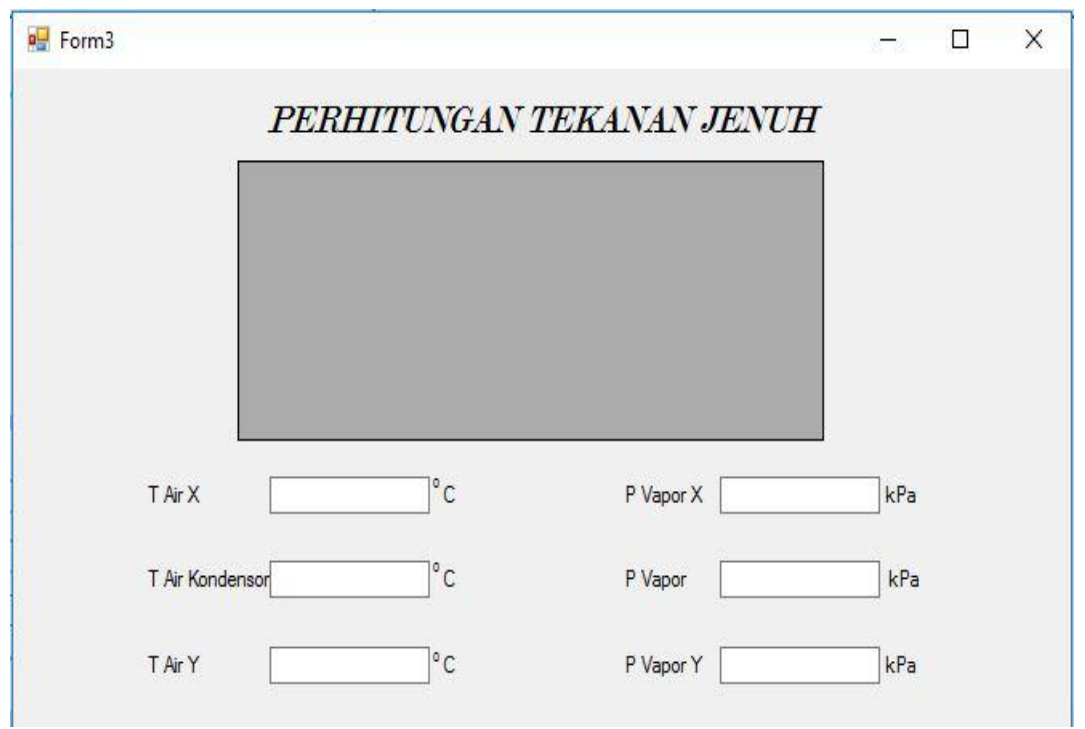

Gambar 4.Form pendukung 3 berfungsi untuk perhitungan nilai tekanan jenuh 
Pengujian pada sistem alarm dilakukan dengan memvariasikan parameter level air dan temperatur air. Level air berkisar antara $300 \mathrm{~mm}$ sampai dengan $1300 \mathrm{~mm}$ berdasarkan pengamatan di lapangan sedangkan temperatur air bervariasi antara $25^{\circ} \mathrm{C}$ sampai dengan $60^{\circ} \mathrm{C}$.Variasi ketinggian air yang akan digunakan untuk pengujian yaitu $300 \mathrm{~mm}$, $550 \mathrm{~mm}, 800 \mathrm{~mm}, 1050 \mathrm{~mm}$ dan $1300 \mathrm{~m}$. Sedangkan variasi pada temperatur air $25^{\circ} \mathrm{C}, 35^{\circ} \mathrm{C}, 50^{\circ} \mathrm{C}$, dan $60^{\circ} \mathrm{C}$.

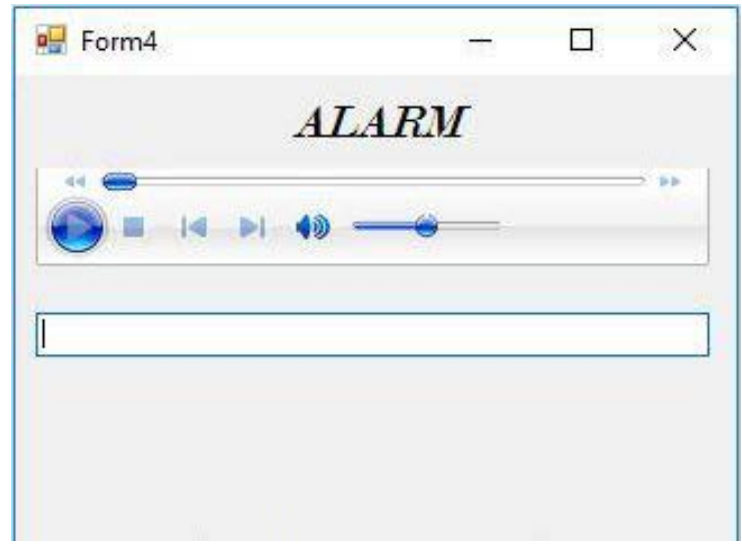

Gambar 5. Form pendukung 4 yang berfungsi untuk menmapilkan alarm

\section{Hasil dan pembahasan}

Kavitasi pada pompa disebabkan oleh nilai NPSHa kurang dari nilai NPSHr [9]. Nilai NPSHr pada unit CEP PT Indonesia Power Adipala sebesar $5.5 \mathrm{~m}$. Data hasil pengujian pada temperatur kondensat $25^{\circ} \mathrm{C}$ dengan variasi level air 300 mm, 550 mm, 800 mm, 1050 mm dan 1300 mm dalam program sistem alarm kavitas menghasilkan tampilan grafik seperti pada Gambar 6.

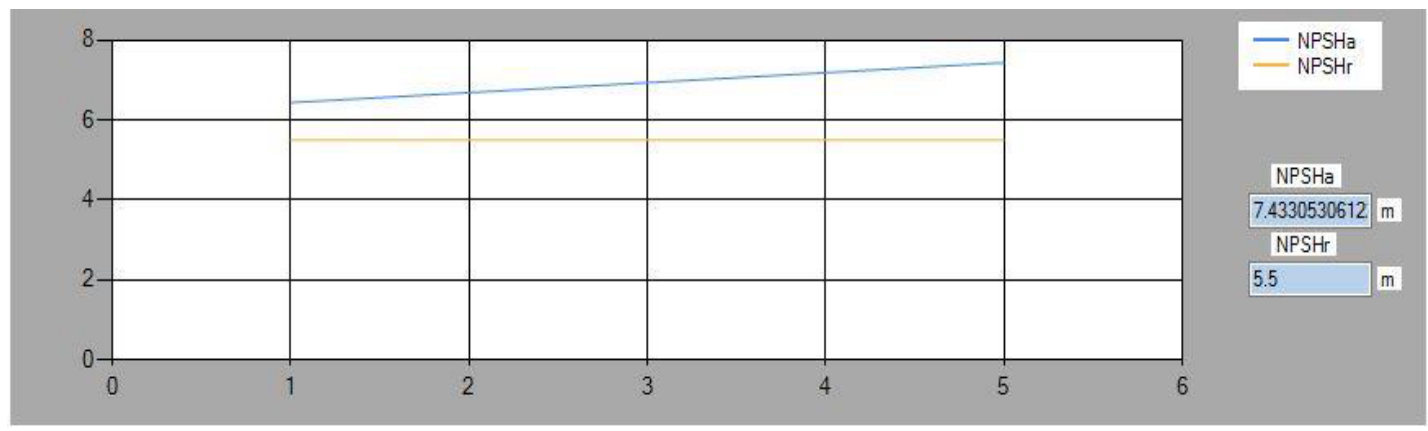

Gambar 6. Tampilan Grafik Hasil Pengujian Pada Temperatur Kondensat $25^{\circ} \mathrm{C}$

Dari grafik tersebut dapat dibaca bahwa kenaikan level air maka nilai NPSHa juga naik. Pada temperature kondensat 250C dengan level air $300 \mathrm{~mm}$ hingga $1300 \mathrm{~mm}$ nilai NPSHa berada diatas nilai NPSHr yaitu 5,5 m dan alarm tidak berbunyi, ini menunjukan bahwa pada tingkat keadaan tersebut Condensate Extraction Pump beroperasi dengan normal tidak berpotensi terjadinya kavitasi. Data hasil pengujian pada temperatur kondensat $35^{\circ} \mathrm{C}$ dengan variasi level air 300 mm, $550 \mathrm{~mm}, 800 \mathrm{~mm}, 1050 \mathrm{~mm}$ dan $1300 \mathrm{~mm}$ dalam program sistem alarm kavitas menghasilkan tampilan grafik seperti pada Gambar 7. 


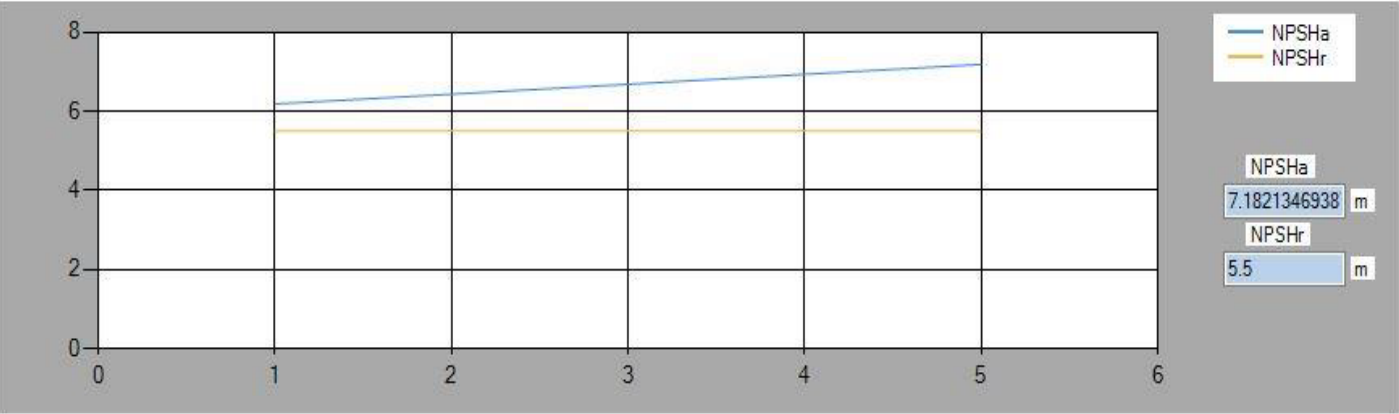

Gambar 7.Tampilan Grafik Hasil Pengujian Pada Temperatur Kondensat $35^{\circ} \mathrm{C}$

Kenaikan temperatur kondensat menjadi $35^{\circ} \mathrm{C}$, dari grafik tersebut juga dapat dibaca bahwa kenaikan level air maka nilai NPSHa juga naik. Pada level air 300 mm hingga 1300 mm nilai NPSHa juga berada diatas nilai NPSHr yaitu 5,5 m dan alarm tidak berbunyi. Data hasil pengujian pada temperatur kondensat $50^{\circ} \mathrm{C}$ dengan variasi level air $300 \mathrm{~mm}, 550$ mm, 800 mm, 1050 mm dan 1300 mm dalam program sistem alarm kavitas menghasilkan tampilan grafik seperti pada Gambar 8.

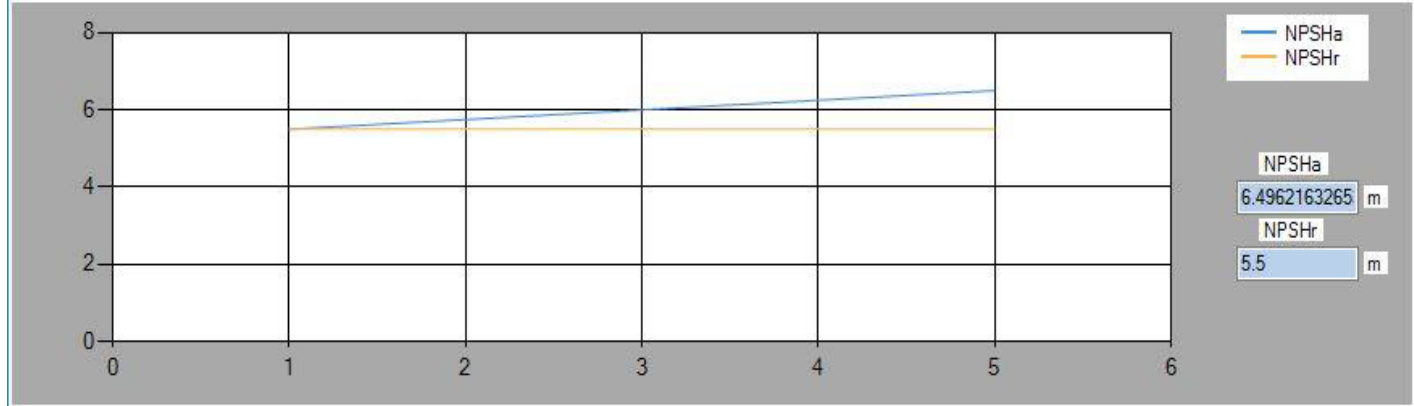

Gambar 8.Tampilan Grafik Hasil Pengujian Pada Temperatur Kondensat $50^{\circ} \mathrm{C}$

Dari grafik tersebut juga dapat dibaca bahwa kenaikan level air maka nilai NPSHa juga naik pada temperatur kondensat menjadi 500 C, kecuali saat level air 300 mm nilai NPSHa di temperature 500C ini dibawah nilai NPSHr sebesar 5,5 m. Pada tingkat keadaan tersebut alarm berbunyi menunjukan bahwa Condensate Extraction Pump beroperasi dalam kondisi kavitasi. NPSHa nilainya diatas NPSHr saat level air 550 mm, 800 mm, 1050 mm dan 1300 mm sehingga CEP beroperasi dalam kondisi normal dan alarm berhenti berbunyi. Data hasil pengujian pada temperatur kondensat $60^{\circ} \mathrm{C}$ dengan variasi level air $300 \mathrm{~mm}, 550 \mathrm{~mm}, 800 \mathrm{~mm}, 1050 \mathrm{~mm}$ dan $1300 \mathrm{~mm}$ dalam program sistem alarm kavitas menghasilkan tampilan grafik seperti pada Gambar 9.

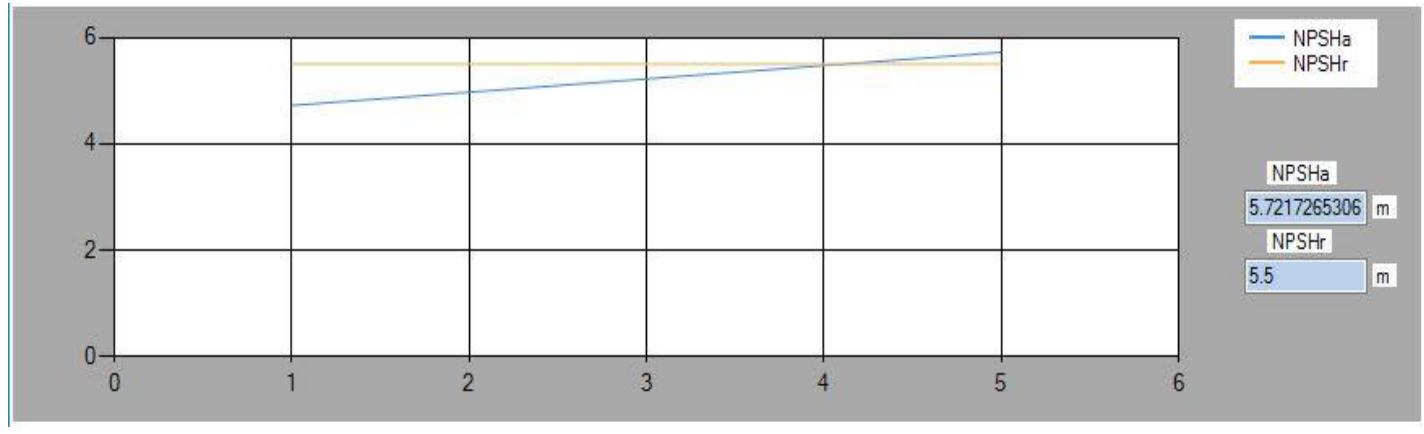

Gambar 9. Tampilan Grafik Hasil Pengujian Pada Temperatur Kondensat $60^{\circ} \mathrm{C}$ 
Pada grafik temperatur kondensat $60^{\circ} \mathrm{C}$ terlihat bahwa pada saat level air $300 \mathrm{~mm}$ sampai $1050 \mathrm{~mm}$ nilai NPSHa berada di bawah nilai NPSHr yaitu $5.5 \mathrm{~m}$ dan alarm berbunyi. Data ini menunjukan bahwa pada temperatur ${ }^{6000}$ Condensate Extraction Pump beroperasi dalam kondisi kavitasi, kecuali pada saat level air pada posisi $1300 \mathrm{~mm}$ pompa beroperasi dalam kondisi normal.Hasil pengujian simulasi dengan memasukan data meliputi tekanan dalam kondensor sebesar - $80 \mathrm{KPa}$ pada pressure gauge atau $21.325 \mathrm{KPa}$ absolut, level air kondensat dari $300 \mathrm{~mm}$ sampai $1300 \mathrm{~mm}$, temperature air kondensat dari $25^{\circ} \mathrm{C}$ sampai $60^{\circ} \mathrm{C}$ dan pada setiap tingkat keadaan dikondisikan sebagai fungsi waktu, dalam program sistem alarm kavitas menghasilkan tampilan grafik seperti pada Gambar 10.

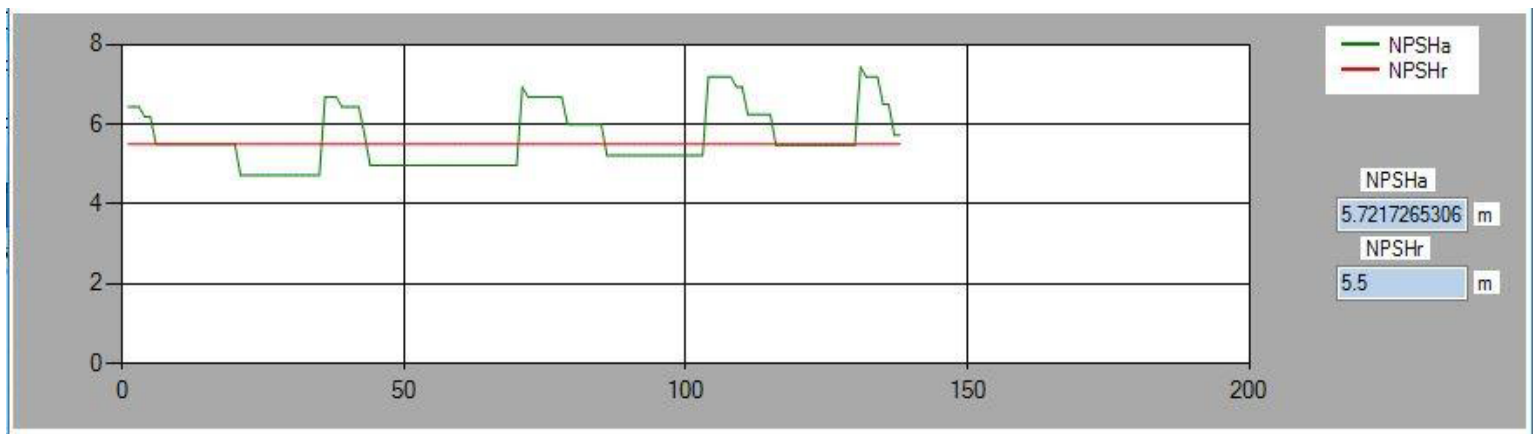

Gambar 10. Tampilan Grafik Hasil Pengujian Simulasi Pada Temperatur Kondensat $25^{\circ} \mathrm{C}$ sampai $60^{\circ} \mathrm{C}$

Berdasarkan simulasi pada program sistem alarm kavitas dengan menggunakan data seperti tersebut di atas dengan interval waktu 1 detik didapatkan hasil grafik fluktuasi nilai NPSHa seperti pada Gambar 10. Program mampu mengolah data parameter - parameter perhitungan pada tingkat keadaan yang bervariasi untuk perhitungan NPSHa.Nilai NPSHa yang dihasilkan ditampilkan dalam bentuk nominal juga dalam bentuk grafik untuk membandingkan dengan NPSHr Condensate Extraction Pump. Perubahan tingkat keadaan mempengaruhi perubahan nilai NPSHa bergantung besarnya perubahan nilai pada masing - masing parameter. Pada saat nilai NPSHa turun hingga dibawah nilai NPSHr program mampu membunyikan alarm yang baru akan berhenti saat nilai NPSHa-nya berada diatas nilai NPSHr. Bunyi alarm ini menandakan bahwa pada tingkat keadaan tersebut Condensate Extraction Pump beroperasi dalam kondisi kavitasi.

Gambar 11 menunjukkan hasil perhitungan NPSHa dan NPSHr pada penelitian yang dilakukan oleh penelitian lain. Gambar 11 menunjukkan karakter NPSH dimana mewakili perbedaan antara suction head dengan tekanan uap pada suhu yang diberikan. Nilai NPSHr tergantung dari jenis pompa yang digunakan, desain pompa dan diperoleh dari uji pompa sentrifugal [10].

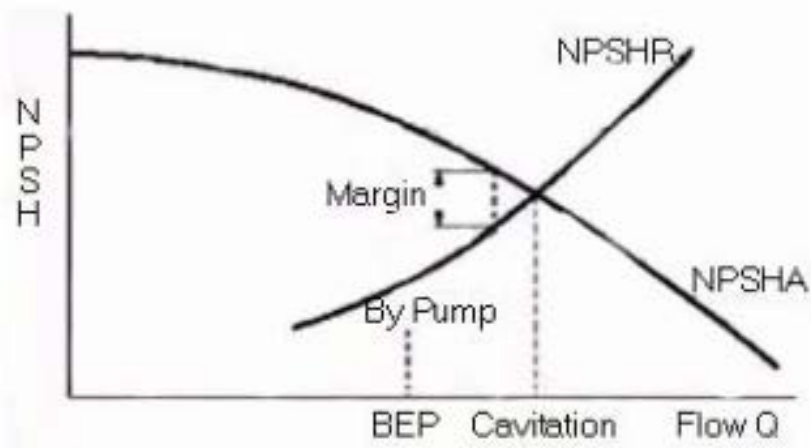

Gambar 11. Grafik karakteristik NPSHa dan NPSHr [10] 


\section{Kesimpulan}

Kesimpulan dapat diambil dari hasil penelitian di atas model program alarm pendeteksi kavitasi pada Condensate Extraction Pump dibuat menggunakan aplikasi Visual Basic berfungsi sesuai dengan yang direncanakan. Berdasarkan penelitian yang telah dilakukan diperoleh hasil yang dapat dilihat pada Tabel 4. Tabel 4 menjelaskan tentang hasil pengujian alarm yang telah dipasang. Semakin tinggi nila temperatur kondensat maka nilai NPSHa akan semakin berkurang.

Tabel 4. Hasil Pengujian Sistem Alarm

\begin{tabular}{cccc}
\hline Temperatur & NPSHa (m) & NPSHr (m) & Kesimpulan \\
\hline $25^{0} \mathrm{C}$ & 7.4 & 5.5 & Tidak terjadi kavitasi \\
$35^{\circ} \mathrm{C}$ & 7.2 & 5.5 & Tidak terjadi kavitasi \\
$50^{\circ} \mathrm{C}$ & 6.5 & 5.5 & Tidak terjadi kavitasi \\
$60^{\circ} \mathrm{C}$ & 5.7 & 5.5 & Tidak terjadi kavitasi \\
\hline
\end{tabular}

Program mampu mempresentasikan nilai NPSHa sistem di setiap perubahan tingkat keadaan dalam bentuk nominal dan grafik.Alarm pada program mampu berbunyi saat nilai NPSHa dibawah nilai NPSHr yang menandakan bahwa pada tingkat keadaan tersebut Condensate Extraction Pum beroperasi dalam kondisi kavitasi.

\section{Daftar Pustaka}

[1] Anta, F., Widodo, A. dan Fajar, B. Deteksi kavitasi pompa sentrifugal dengan Analisi Sinyal Getaran. Indonesia: Universita Diponegoro; 2013. p. 5-6.

[2] Kamiel, Berli P., Nafsaka, Deby A., Riyanta, B. dan A., Azhim. Deteksi Kavitasi Pada Pompa Sentrifugal Menggunakan Spektrum Getaran dan Spektrum Envelope. Semesta Teknika. 2019 Mei; 22(01): p. 1-2.

[3] Kamiel, Berli P., P., Niko dan Riyanta, B. Ekstraksi Parameter Statistik Domain Waktu dan Domain Frekuensi untuk Mendeteksi Kavitasi pada Pompa Sentrifugal Berbasis Principal Component Analysis (PCA). Rekayasa Mesin. 2019. 10(02): p. 165-166.

[4] Al Hasmi, Salem A., R. El-Hesnawi, Mohammed and A. Ball. Processing Vibration Signals ForCavitation Detection. Journal of Sebaa University--(Pure and Apllied Sciences). 2017. 6(02): p.1-2.

[5] Kotb, Ashraf and Abdulaziz, A.M.Cavitation Detection in Variable Speed Pump by Analyzing the Acoustic and Vibration Spectrums. Engineering. 2015 October. 7(10): p. 706-716.

[6] Dong, L., Wu, K., Zhu, JC., et.al. Cavitation Detection in Centrifugal Pump Based on Interior Flow-Borne Noise Using WPD-PCA-RBF. Shock and Vibration.2019 Mei. p. 1-12.

[7] PT Indonesia Power Adipala. Datasheet Unit Condensate Extraction Pump (CEP). 2018.

[8] Gillain \& Co. Alfa Laval Pump Handbook Second Edition.Belgium: Boomsesteenweg; 2002. p 157.

[9] Schiavello, B and Visser, F. C. Pump Cavitation - Various NPSHR Criteria, NPSHA Margins, and Impeller Life Expectancy. Proceedings of The Twenty Fifth International Pump UsersSymposium;22 April 2008; New Jersey, United States. Semanticscholar; 2009.

[10] Al Hasiefni, S. A., et al. Cavitation Detection Of A Centrifugal Pump Using Instantaneous Angular Speed. Proceeding of $7^{\text {th }}$ Biennial ASME conference on Engineering Systems Design and Analysis. 2004. 